\title{
THE EFFECT OF DESFERRIOXAMINE ON IRON METABOLISM AND LIPID PEROXIDATION IN HEPATOCYTES OF C57BL/10 MICE IN EXPERIMENTAL UROPORPHYRIA
}

\author{
Warry van Gelder, Peter D. Siersema, ${ }^{*}$ Arthur Voogd, $\dagger$ \\ Nel C. M. DE JeU-Jaspars, Henk G. VAN EIJK, $\ddagger$ Johan F. Koster, $\uparrow$ \\ FELIX W. M. DE ROOY* and J. H. PAUL WILSON* \\ Dept of Chemical Pathology, Erasmus University Rotterdam, *Dept of Internal Medicine II, \\ AZR/Dijkzigt, and †Dept of Biochemistry, Erasmus University Rotterdam, The Netherlands
}

(Received 29 October 1992; accepted 19 April 1993)

\begin{abstract}
The effects of the iron chelator desferrioxamine (DFx) on liver iron accumulation, malondialdehyde (MDA) production, porphyrin accumulation and uroporphyrinogen decarboxylase (UROD; EC 4.1.1.37) activity were investigated over a period of 14 weeks in C57BL/10 mice, made porphyric by the administration of hexachlorobenzene (HCB) and iron-dextran (Imferon, IMF) or IMF alone. In addition, we measured the amount of low molecular weight (LMW) iron in liver tissue to determine a possible correlation with MDA production. These experiments showed that combined treatment with HCB + IMF, as well as IMF alone, resulted in porphyrin accumulation, increased MDA production and reduced URO-D activity, whereas HCB alone had no effect. DFx caused a reduction in hepatic porphyrins, this reduction being more distinct in the IMF group than in the HCB + IMF group. The effect of DFx on MDA production and URO-D activity was in agreement with the results on porphyrin accumulation. LMW iron pool measurements at 11 weeks correlated well with data on MDA production in all treated groups in that period $\left(r^{2}=0.84\right)$, suggesting both variables are interdependent. In conclusion, these results suggest an important role for iron in porphyrin accumulation, probably through its catalytic role in the generation of oxygen-related free radicals, resulting in direct damage to UROD. The effectiveness of DFx in reducing porphyrin accumulation is probably the result of a reduction in LMW iron, thus diminishing the amount of iron available for a catalytic role in the generation of oxygen-related free radicals.
\end{abstract}

Both experimental uroporphyria and human porphyria cutanea tarda are characterized by a partial block in the haem biosynthetic pathway at the level of uroporphyrinogen decarboxylase (URO-D;§ EC 4.1.1.37) and by the accumulation of uroporphyrins and heptacarboxylporphyrins in the liver [1]. Uroporphyria can be induced in rodents and humans by the administration of hexachlorobenzene (HCB), a polyhalogenated aromatic hydrocarbon [2].

As in human porphyria cutanea tarda, iron plays an important role in polyhalogenated aromatic hydrocarbon-induced porphyria; porphyria develops faster if animals are made siderotic [3-12]. In addition the administration of Imferon (IMF), an iron-dextran complex, to C57BL/10 mice, by itself leads to porphyrin accumulation [10-12]. Iron deficiency due to bleeding [5] or treatment with desferrioxamine (DFx) $[13,14]$, an iron chelator,

$\ddagger$ Corresponding author: Prof. Dr H. G. van Eijk, Erasmus University Rotterdam, Medical Faculty, Dept of Chemical Pathology, Room EE 600, P.O. Box 1738, 3000 DR Rotterdam, The Netherlands. Tel. (31) 10-4087451; FAX (31) 10-4362841.

$\$$ Abbreviations: DFx, desferrioxamine; MDA, malondialdehyde; URO-D, uroporphyrinogen decarboxylase; HCB, hexachlorobenzene; IMF, iron-dextran; LMW, low molecular weight. diminishes or completely prevents the development of porphyria in animals $[6,8,15,16]$. The effect of iron has been explained by its ability to participate in iron-catalysed free radical-mediated processes $[8,10,11,17-19)$. If in hepatocytes, either as a result of cytochrome $\mathbf{P} 450$ induction or as a result of (genetically determined) active oxidative metabolism in certain species, reactive oxygen species are produced and "free" iron is also present, highly reactive oxygen-related free radicals could be formed by the Haber-Weiss reaction [20, 21]. In addition, the intracellular presence of free ferrous iron itself can induce the formation of $\mathrm{O}_{2}^{-}$(superoxide) $[22,23]$ and thus initiate the chain of reactions leading to the formation of oxygen-related free radicals. In the presence of oxygen-related free radicals a variety of reactions could be initiated, such as the peroxidation of membrane lipids [24]. Recently, we suggested that the process of lipid peroxidation is involved in the pathogenesis of experimental uroporphyria $[8,18]$.

Since the effect of the iron chelator, DFx, on liver iron accumulation, malondialdehyde (MDA) production (as a marker of lipid peroxidation), porphyrin accumulation and URO-D activity in the course of time has not been studied extensively, we decided to investigate this in livers of C57BL/10 mice, made porphyric by the administration of 
$\mathrm{HCB}+\mathrm{IMF}$ or IMF alone. The nature of the iron pool involved in experimental porphyria is not clear. On the basis of the finding of a morphological cooccurrence of uroporphyrin crystals and ferritin iron in hepatocytes of porphyric $\mathrm{C} 57 \mathrm{BL} / 10$ mice, we suggested a role for ferritin-bound iron in the pathogenesis of experimental porphyria [12]. However, ferric iron in ferritin is sequestered in a non-toxic oxyhydroxide, complexed with phosphate. The release of iron from ferritin requires reduction [25]. Although in vitro release of ferrous iron from ferritin by liver microsomes has been described $[9,26-29]$, it is not clear whether this also occurs in vivo. An alternative possibility is an intracellular pool of low molecular weight (LMW) iron, as suggested by Jacobs [30] and others [31-33]. A role for this LMW iron has been demonstrated in free radical formation in iron-loaded cells $[23,34,35]$. A recentiy developed technique [35] to measure the amount of LMW iron in tissue homogenates was used to elucidate this problem further.

\section{MATERIALS AND METHODS}

Chemicals. HCB was purchased from Merck AG (Darmstadt, Germany), ferrihydroxide-dextrane (IMF) was purchased from Fisons Pharmaceuticals (Leusden, The Netherlands), Ethrane (Enfluraan) was purchased from Abbott B.V. (Amstelveen, The Netherlands) and deferoxaminmesilate (Desferal) was purchased from Ciba-Geiby B.V. (Arnhem, The Netherlands). All other chemicals were of the highest purity commercially available.

Animals and treatment. This study was performed in accordance with the "Regulations for the use of laboratory animals at the Frasmus University Rotterdam", laid down by the Laboratory Animal Committee of the Erasmus University. Male C57BL/ 10 mice, 9-11 weeks of age and weighing $20-25 \mathrm{~g}$, were purchased from Centraal Proefdier Bedrijf (Zeist, The Netherlands)

HCB treatment consisted of two intraperitoneal (i.p.) injections of $8 \mathrm{mg} \mathrm{HCB}(400 \mathrm{mg} / \mathrm{kg}$ body weight) dissolved in $0.25 \mathrm{~mL}$ warm corn oil, with 1 week interval. Mice treated with IMF received a single i.p. injection of $12 \mathrm{mg}(600 \mathrm{mg} / \mathrm{kg}$ body weight).

Treatment with DFx consisted of daily i.m. injections of $5 \mathrm{mg} \mathrm{DFx}(250 \mathrm{mg} / \mathrm{kg}$ body) in $0.05 \mathrm{~mL}$ sterile water, administered alternately to the hind legs. When both HCB and IMF were given, IMF was given 3 days after the second injection of HCB. HCB and IMF were injected under Ethrane anaesthesia.

Twenty mice were given HCB alone (HCB), 25 mice the combination of $\mathrm{HCB}$ and IMF (HCB + IMF) and 25 mice IMF alone (IMF). DFx administration started either immediately (HCB + IMF + DFx; 25 mice and IMF + DFx; 25 mice) or at 7 weeks (HCB + IMF + DFx 7; 15 mice and $\mathrm{IMF}+\mathrm{DFx} 7 ; 15$ mice) to provide information on the effectiveness of DFx in reversing the changes induced by IMF and/or HCB. Twenty mice were not treated at all and served as controls (control group).

In order to obtain blood-free livers, mice were anaesthetized with Ethrane, the vena cava inferior was cannulated and the liver was perfused with a $0.15 \mathrm{M} \mathrm{NaCl}$ solution at room temperature until the fluid leaving the liver was clear (the average perfusion time was $3 \mathrm{~min}$ ). Livers were removed, weighed and processed for further measurements. Measurements were performed before treatment ( 0 weeks) and at $4,7,11$ and 14 weeks after treatment with $\mathrm{HCB}$ and IMF and with IMF alone.

Hepatic porphyrins. These were measured using a modification of the method described by Lim et al. [36]. Briefly, $300 \mathrm{mg}$ of liver tissue were homogenized (glass on glass, manual) to yield a $10 \%$ homogenate in water, which was then centrifuged at $10,000 \mathrm{~g}$ for $4 \mathrm{~min}$. The supernatant was stored at $-20^{\circ}$ until further processing. To $0.1 \mathrm{~mL}$ of the homogenate, $0.1 \mathrm{~mL}$ of Tris- $\mathrm{HCl}(50 \mathrm{mmol} / \mathrm{L}$, $\mathrm{pH} 8.0$ ) and $0.8 \mathrm{~mL}$ of a "mix" were added. The "mix" contained: $25 \mathrm{~mL}$ dimethyl sulphoxide $(100 \% \mathrm{w} / \mathrm{v}), 10 \mathrm{~mL}$ trichloric acid $(50 \% \mathrm{w} / \mathrm{v})$, $10 \mathrm{~mL} \mathrm{HCl}(1 \mathrm{~mol} / \mathrm{L}), p$-Benzoquinon $(2.3 \mathrm{mmol} / \mathrm{L})$ (Merck-Schuchandt, Hohenbrunn, Germany) [37] and $35 \mathrm{~mL}$ of distilled water. This was stirred and centrifuged for $15 \mathrm{~min}$ at $1800 \mathrm{~g}$. The porphyrins in the supernatant were measured by reversed-phase HPLC [37]. Protein was measured according to Lowry et al. [38], and the amount of porphyrins expressed in picomoles per milligram protein.

Hepatic URO-D activity. To $0.1 \mathrm{~mL}$ of a $1 U \%$ homogenate of liver tissue (as described above), $0.05 \mathrm{~mL}$ of DL-dithiothreitol $(30 \mathrm{mmol} / \mathrm{L})$ in Tris$\mathrm{HCl}(50 \mathrm{mmol} / \mathrm{L}, \mathrm{pH} 8.0)$ (Sigma Chemical Co., St Louis, MO, U.S.A.) was added to restore the activity of the enzyme uroporphyrinogen-III-synthase (EC 4.2.1.75) [37], followed by incubation for $30 \mathrm{~min}$ at $4^{\circ}$. Then, $0.05 \mathrm{~mL}$ of porphobilinogen $(0.8 \mathrm{mg})$ in $5 \mathrm{~mL}$ of EDTA $(4 \mathrm{mmol} / \mathrm{L})$ in Tris- $\mathrm{HCl}(50 \mathrm{mmol} /$ $\mathrm{L}, \mathrm{pH} 8.0$ ) was added, or followed by incubation for $60 \mathrm{~min}$ at $37^{\circ}$ [39]. The reaction was stopped by adding $0.8 \mathrm{~mL}$ of the "mix" (as described above). This was stirred and centrifuged for $15 \mathrm{~min}$ at $1800 \mathrm{~g}$. The porphyrins in the supernatant were measured by reversed-phase HPLC [36]. Protein was measured according to Lowry et al. [38] and the amount of porphyrins formed was expressed in picomoles per milligram protein.

Total liver iron content. This was measured by a modification [12] of the method described by Harris [40]. Liver tissue was dried at $110^{\circ}$ overnight. The dried liver tissue was weighed, $0.5 \mathrm{~mL}$ perchloric acid $(70 \% \mathrm{w} / \mathrm{v})$ was added and the solution was heated until colourless. After cooling, distilled water was added to a final volume of $2.0 \mathrm{~mL}$. From this solution $0.2 \mathrm{~mL}$, was taken and $0.1 \mathrm{~mL} \mathrm{HCl}(1 \mathrm{~mol} /$ L), $0.2 \mathrm{~mL} \mathrm{L-ascorbic} \mathrm{acid}(0.14 \mathrm{~mol} / \mathrm{L}), 0.1 \mathrm{~mL}$ sodium acetate (saturated) and $0.2 \mathrm{~mL}$ Ferrozine $(10 \mathrm{mmol} / \mathrm{L})($ Sigma) were added. This solution was mixed thoroughly and after $10 \mathrm{~min}$ the absorbance was measured at $562 \mathrm{~nm}$ against three standard iron solutions. The amount of iron was expressed in micromoles per gram dry weight.

Total protein measurements [41]. A small sample of liver tissue was homogenized (Ultrathurax, Janke and Kunkel, Germany), followed by stepwise dilution. To $100 \mu \mathrm{L}$ of the $0.1 \%$ homogenate, $5 \mathrm{~mL}$ of Coomassie brilliant blue was added and after 
$10 \mathrm{~min}$ the absorbance was measured at $595 \mathrm{~nm}$. The results were compared with four different standard solutions of bovine serum albumin (Pierce, Rockford, IL, U.S.A.) in the range of $100-400 \mu \mathrm{g} / \mathrm{mL}$. The amount of protein was expressed in micrograms per gram wet weight.

$M D A$. This was measured using the method described by Kornbrust and Mavis [42] and Wilson et al. [43]. Four aliquots $(0.25,0.5,0.75$ and $1.0 \mathrm{~mL})$ of a $10 \%$ (wet $w / v$ ) liver tissue homogenate in a $\mathrm{KCl} / \mathrm{Tris}-\mathrm{HCl}$ buffer $(0.15 \mathrm{~mol} / \mathrm{L}, 5 \mathrm{mmol} / \mathrm{L}, \mathrm{pH}=$ 7.8) were filled up to a final volume of $1.0 \mathrm{~mL}$ with the same buffer solution. To each of these samples, $0.3 \mathrm{~mL}$ trichloric acid $(20 \% \mathrm{v} / \mathrm{v}), 0.6 \mathrm{~mL} 2-$ thiobarbituric acid $(0.05 \mathrm{~mol} / \mathrm{L})$ and $0.1 \mathrm{~mL} 2,6 \mathrm{di}$ tert-butyl-4-methylphenol (BHT) $(0.2 \%$ in ethanol, $\mathrm{w} / \mathrm{v})$ were added. The solution was mixed and centrifuged $(10 \mathrm{~min}, 2800 \mathrm{~g})$. The supernatant was heated for $8 \mathrm{~min}$ at $100^{\circ}$ and immediately cooled. Subsequently, the absorbance was measured $(535 \mathrm{~nm}, \varepsilon=156,000)$ and the results were compared to a standard solution of MDA, treated in the same manner.

$L M W$ iron. Amounts of $\mathrm{LMW}$ iron were measured after 11 weeks of treatment, by a method developed by Voogd et al. [35]. Some modifications were necessary, due to the limited quantity of liver tissue available for analysis.

A $10 \%(\mathrm{w} / \mathrm{v})$ liver homogenate in Tris- $\mathrm{HCl}$ (100 mmol/L, $\mathrm{pH} 7.4$ ) was centrifuged for $15 \mathrm{~min}$ at $\left.10,000 \mathrm{~g}, 0^{\circ}\right)$. To $1 \mathrm{~mL}$ of the supernatant, $100 \mu \mathrm{L}$ DFx ( $22 \mathrm{mmol} / \mathrm{L})$ were added and the samples were incubated for $5,15,30$ and $60 \mathrm{~min}$ at $37^{\circ}$. To stop the reaction between the available iron and DFx, samples were passed through a SEPPAK C18 cartridge (Millipore Corp., Milford, U.S.A.) immediately after incubation. Prior to use, the cartridges were conditioned by means of pre-elution with $5 \mathrm{~mL}$ methanol, followed by $5 \mathrm{~mL}$ distilled water. After adding the samples, cartridges were flushed with
$5 \mathrm{~mL}$ distilled water. In this way ferrioxamine (Fx) and DFx were retained, while most other compounds were eluted. Fx and DFx were subsequently eluted from the SEPPAK with $1 \mathrm{~mL}$ methanol and the effluent was applied to a HPLC RP 18 column $(250 \times 4 \mathrm{~mm}$ i.d., Merck). The mobile phase consisted of $\mathrm{Na}_{2} \mathrm{HPO}_{4} / \mathrm{NaH}_{2} \mathrm{PO}_{4}$, acetonitrile (88\%, $20 \mathrm{mmol} / \mathrm{L}, 12 \%)$, sodium-EDTA $(2 \mathrm{mmol} / \mathrm{L})$ and ammonium acetate $(1 \mathrm{~mol} / \mathrm{L})$. HPLC analysis was performed on a dual pump LKB system with automatic sample injector and two variable wavelength detectors, to measure Fx $(430 \mathrm{~nm})$ and DFx $(229 \mathrm{~nm})$ simultaneously in the effluent. The results (duplicate samples, 4-fold measurements per sample) were compared to three standard amounts of iron, treated in the same manner as the liver samples.

Statistical data analysis. All measurements are presented as means $\pm S D$. Differences within and between groups were evaluated by one-way analysis of variance. As multiple groups were compared, we used a one-way analysis procedure with a Bonferroni correction option in STATA release 2 (Computing Resource Center, Los Angeles, CA, U.S.A.). Results were considered significant if $\mathbf{P}<0.05$.

\section{RESULTS}

\section{Total liver iron content (Fig. 1)}

The liver iron content in the IMF group was significantly increased at 4 weeks, but even in the following 10 weeks a distinct rise could be measured. Liver iron content in the IMF + DFx group was significantly lower at all times, compared to the IMF group $(P<0.001)$. In the $I M F+D F x 7$ group, liver iron content decreased after starting $\mathrm{DFx}$ administration at 7 weeks, resulting in about a $50 \%$ liver iron reduction at 14 weeks. The increase in liver iron content in the HCB + IMF group was equal to that in the IMF group. However, in the $\mathrm{HCB}+\mathrm{IMF}+\mathrm{DFx}$ group, liver iron contents were

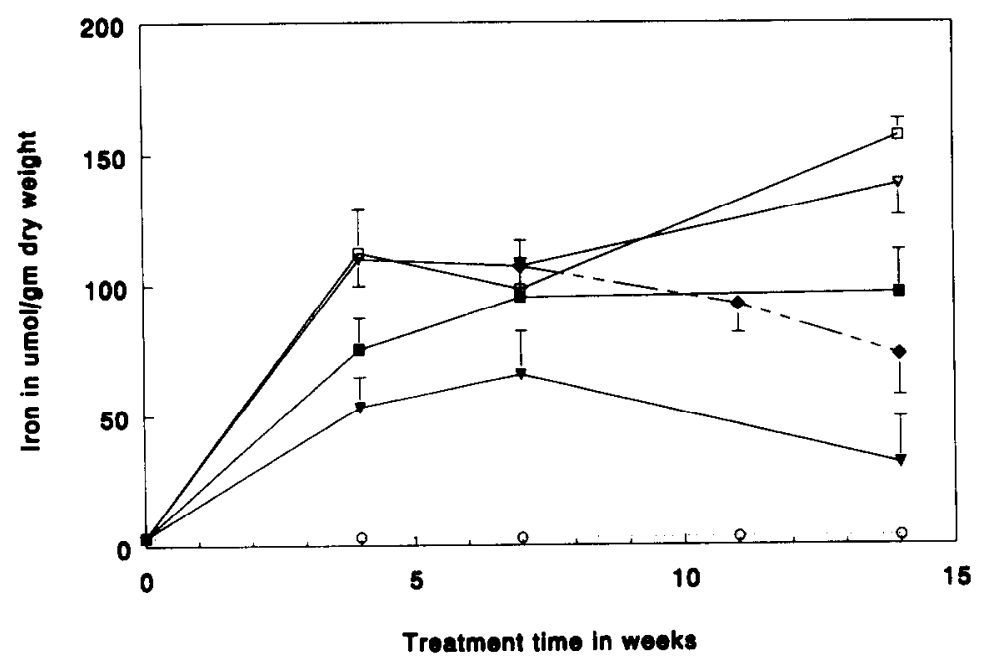

Fig. 1. Liver iron concentration during the experimental period. Iron concentrations were measured in duplicate samples of liver tissue of CS7BL/10 mice. Open circles: control group. Open triangles: IMF group. Closed triangles: IMF + DFx group. Open squares: HCB + IMF group. Closed squares: HCB + IMF + DFx group. Closed diamonds: IMF + DFx7 group. Values shown represent the means $\pm \mathrm{SD}$ 


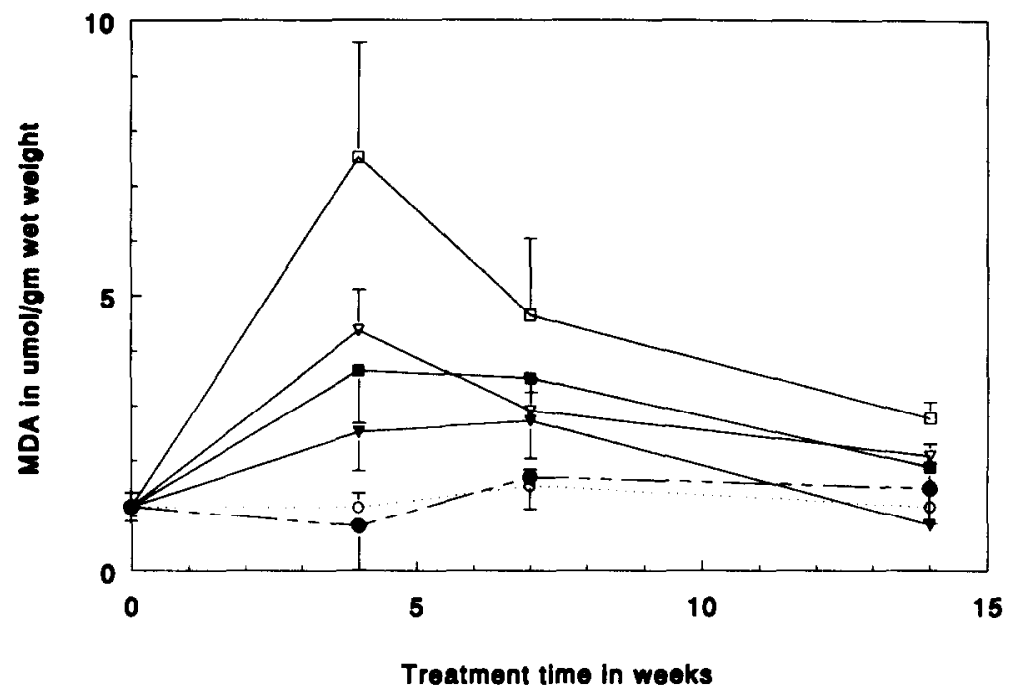

Fig. 2. Liver MDA concentration during the experimental period. MDA concentrations were measured 4-fold in samples of liver tissue of C57BL/10 mice. Open circles: control group. Closed circles: HCB group. Open triangles: IMF group. Closed triangles: IMF + DFx group. Open squares: HCB + IMF group. Closed squares: HCB + IMF + DFx group. Values shown represent the means \pm SD.

significantly elevated at all times, compared to the iron results in the IMF + DFx group $(\mathrm{P}=0.008)$. In contrast, liver iron content in the non-treated control mice was very low, with an average of $3 \mu \mathrm{mol} / \mathrm{g}$ dry wt liver tissue.

\section{Liver MDA concentration (Fig. 2)}

In all treated groups the highest MDA contents were found after 4 weeks of treatment, followed by a reduction in liver MDA, depending on the nature of the treatment. All DFx-treated groups showed a distinct reduction in MDA production compared to those groups receiving the same treatment without
DFx. In the IMF + DFx group, MDA production at 14 weeks was even lower than that in the control groups. Treatment with HCB + IMF resulted in higher MDA concentrations than treatment with IMF alone; DFx reduced these differences.

\section{Total liver porphyrins (Fig. 3)}

Significant porphyrin accumulation was not detected during the experimental period in livers of the control group, nor in livers of the HCB group. The IMF group showed a continuous increase in hepatic porphyrin accumulation during the 14 weeks. Apart from the results at 14 weeks, the hepatic

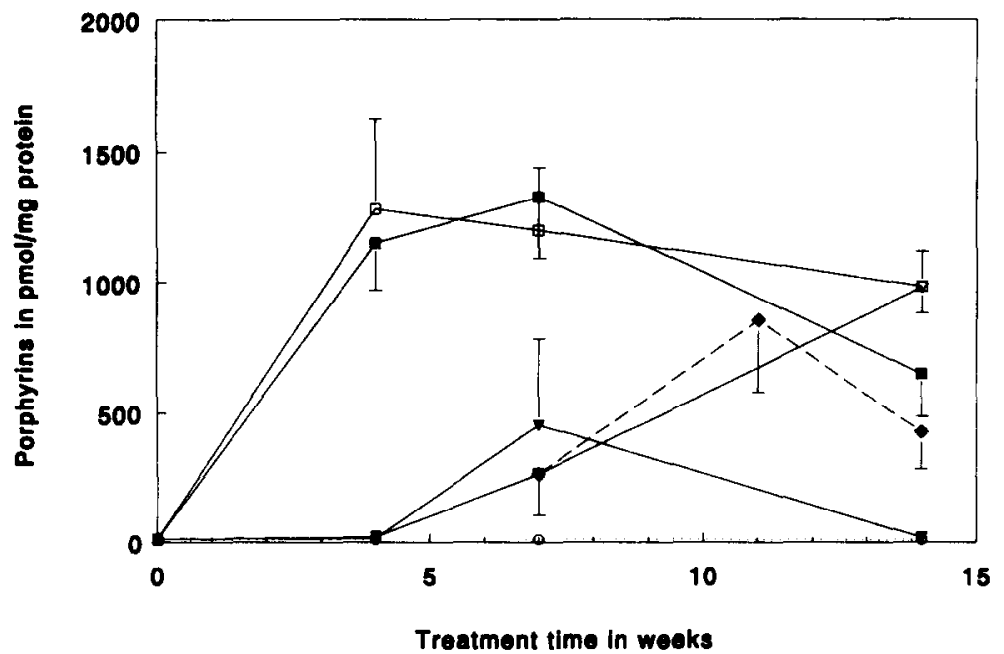

Fig. 3. Liver porphyrin accumulation during the experimental period. Porphyrin concentrations were measured as described in Materials and Methods. Open circles: control group. Open triangles: IMF group. Closed triangles: IMF + DFx group. Open squares: HCB + IMF group. Closed squares: HCB + IMF + DFx group. Closed diamonds: IMF + DFx7 group. Values shown represent the means \pm SD. 


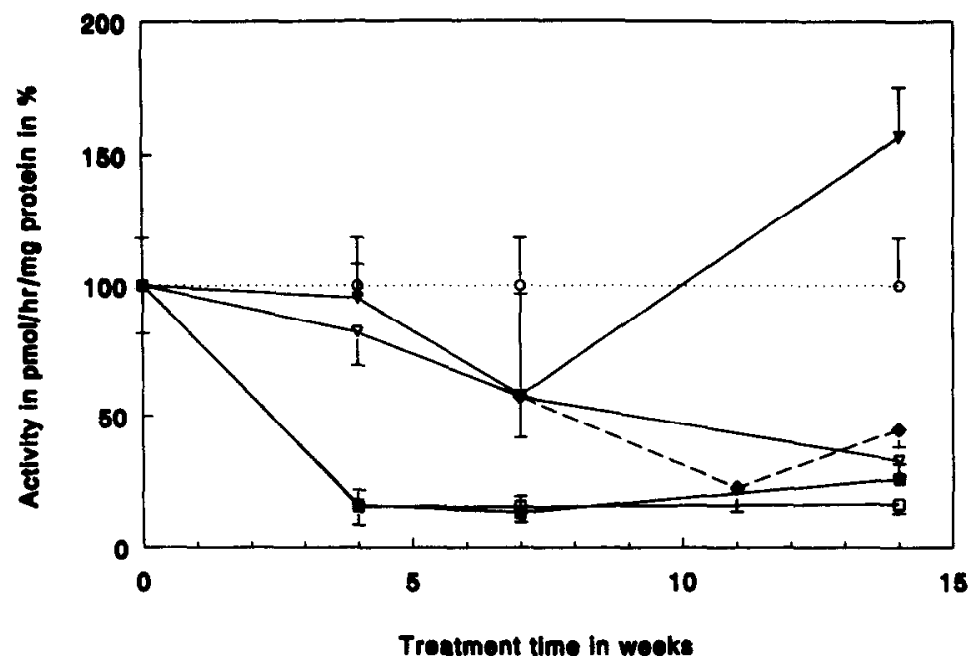

Fig. 4. Liver URO-D activities during the experimental period. URO-D activities were measured as described in Materials and Methods and expressed as percentages of activity of the control group (100\%: $161 \mathrm{pmol} / \mathrm{hr} / \mathrm{mg}$ protein). Open circles: control group. Open triangles: IMF group. Closed triangles: IMF + DFx group. Open squares: HCB + IMF group. Closed squares: HCB + IMF + DFx group. Closed diamonds: IMF + DFx 7 group. Values shown represent the means $\pm S D$.

porphyrin concentration in the HCB + IMF group was significantly higher than in the IMF group $(P<0.001)$. The reduction in porphyrin accumulation was more pronounced in livers of the $\mathrm{IMF}+\mathrm{DFx}$ group than in the HCB + IMF + DFx group.

\section{Liver URO-D activities}

Apart from livers in the control group, a strong negative correlation $(-0.80$ to -0.92$)$ was found between porphyrin accumulation and URO-D activity data in all treated groups. Liver URO-D activity showed an increase at 14 weeks in the $\mathrm{IMF}+\mathrm{DFx}$ and IMF + DFx 7 group. In the first 4 weeks, URO-D activity in all HCB + IMF treated groups diminished to $\pm 15 \%$ of control group values and did not recover during the latter part of the experimental period (Fig. 4).

\section{LMW iron pool content (Fig. 5)}

The results on LMW iron pool content at 11 weeks were compared with data on MDA production around that time. Calculations yielded a correlation coefficient of 0.84 , thus indicating that the two variables are interdependent.

\section{DIscussion}

In accordance with previous studies, we confirmed

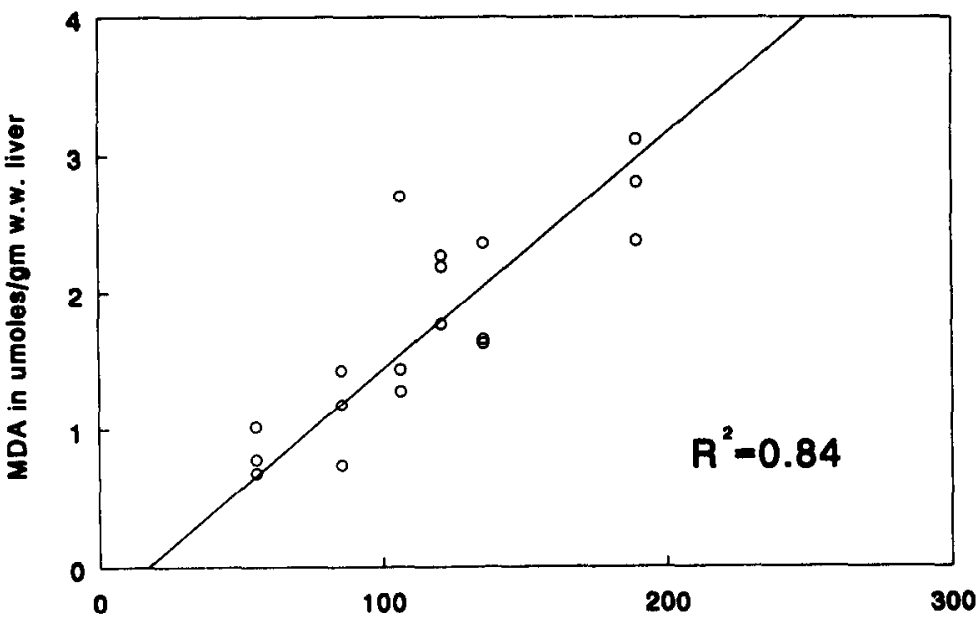

LMW pool iron in nmoles/gm w.w. liver

Fig. 5. Liver LMW pool iron concentrations compared to liver MDA concentrations after 11 weeks of treatment. Results of LMW iron pool measurements after 11 weeks were compared to MDA concentration results from that period. Open circles represent individual results. Calculations yielded a correlation coefficient of $\mathbf{0 . 8 4}$ 
that treatment of $\mathrm{C} 57 \mathrm{BL} / 10$ mice with $\mathrm{HCB}$ and IMF, but also with IMF alone, resulted in the accumulation of (uro)porphyrins in the liver. In this strain of mice, HCB alone did not produce uroporphyria [10-12]. These results (amongst others) point to an important role for iron in the pathogenesis of this form of uroporphyria.

Three major mechanisms for the role of iron in experimental uroporphyria have been proposed. (i) Iron $\left(\mathrm{Fe}^{2+}\right)$ binds directly to one or more sulfhydryl groups of URO-D [44-46]. This would inactivate the enzyme, which needs free sulfhydryl group(s) for its catalytic activity $[44,47]$. When (under aerobic conditions) URO-D is incubated with iron in the presence of an electron donor, a reduction in enzyme activity can be measured [44]. (ii) This could be the result of free radical-mediated damage to URO-D itself [44], or (iii) the result of oxidation of uroporphyrinogens to uroporphyrins that inhibit enzyme activity $[11,15,48]$.

In general, it is not clear whether the direct interaction of ferrous iron and URO-D also occurs in vivo. Mukerji et al. $[44,45]$ found that $\mathrm{Fe}^{2+}$ concentrations in the range of $0.1-1.0 \mathrm{mM}$ were required in vitro to reduce the activity of partially purified URO-D. In our view, these $\mathrm{Fe}^{2+}$ concentration requirements cannot be met in vivo [49]. However, our experimental results do not preclude the possibility of direct interaction between ferrous iron and URO-D. In fact, we found that IMF alone reduced URO-D activity and caused concomitant porphyrin accumulation. The relatively slow onset of porphyrin accumulation (as compared to the rapid accumulation of iron, cf. Fig. 1 to Fig. 3 ) could be explained by the results of a morphological examination of the liver tissue of IMF-treated mice [50]. Iron-positive granules were present in Kupffer cells shortly after administration of IMF, but it took another 2 weeks before iron accumulation could be detected in the hepatocytes. As a rule, the accumulation of ferritin iron preceded porphyrin accumulation in hepatocytes [50]. Liver iron measurements do not detect this intraheptatic "iron shift" and give the sum of the iron content of both cell types. Therefore, these results are not an actual representation of the amount of iron accumulated in hepatocytes. Experimental results in the IMF + DFx group, however, partially contradict the possible interaction of ferrous iron and URO-D. At 14 weeks, URO-D activity was completely restored and accumulated porphyrins had disappeared, despite the fact that the liver iron concentration was still 10 times higher than in the control group.

In recent years, there has been a growing interest in the role of iron and other trace metals as mediators in the production of oxygen-related free radicals. In our experiments, treatment with IMF resulted in increased MDA production, which was maximal at 4 weeks, but was still significantly increased at 14 weeks ( $P=0.004$, Fig. 2$)$, despite the fact that most iron will be stored in ferritin by this time. MDA production at 14 weeks in the IMF + DFx group is significantly lower than in the IMF group $(P<0.001)$. This could explain why URO-D activity was restored at that time, despite the presence of an iron excess in the liver. Moreover, the LMW iron results in the
IMF + DFx group $[55 \pm 12.6 \mathrm{nmol} / \mathrm{g}$ wet wt liver tissue (mean \pm SD)] were also lower than those in the IMF group $(120.8 \pm 15.1 \mathrm{nmol} / \mathrm{g}$ wet $\mathrm{wt})$ and confirmed our data on MDA production (Fig. 5). These results support the theory of URO-D inactivation as a result of free radical-mediated damage.

HCB causes the induction of microsomal cytochrome P450IA2 [51,52] and this enzyme could promote oxidation of uroporphyrinogens. However, it is more likely that cytochrome P450IA2 induction leads to the generation of reactive oxygen species $[21,53]$. HCB alone did not induce porphyrin accumulation in C57BL/10 mice [12], neither did it affect MDA production. Combined treatment with HCB + IMF, however, resulted in increased MDA production, porphyrin accumulation and decreased URO-D activity as compared to the IMF group (Fig. 2). These differences between the IMF and $\mathrm{HCB}+\mathrm{IMF}$ groups were statistically significant for all results except those at 14 weeks $(P<0.004)$. In contrast, liver iron measurements (Fig. 1) as well as morphological studies [50] showed more or less equal results in both groups. The effects of DFx in the $\mathrm{HCB}+\mathrm{IMF}+\mathrm{DFx}$ group were less pronounced than in the IMF + DFx group as compared to their non-DFx treated counterparts. Still, the results at 14 weeks in the HCB + IMF + DFx group are significantly different from those in the HCB + IMF group $(P=0.008)$, with the exception of the results on URO-D activity. In Fig. 4 it appears that URO$D$ activity in the $\mathrm{HCB}+\mathrm{IMF}+\mathrm{DFx}$ group increases, but measurements over a longer period of time will be necessary to confirm this trend. Our results support the idea that HCB stimulates the production of oxygen free radicals in the presence of iron. This is further illustrated by the fact that $\mathrm{HCB}$ alone will not induce porphyria in C57BL/10 mice, probably due to the very low levels of total liver iron in the non-treated animals $[5,7,54]$. In our view, DFx reduces the amount of iron available for a catalytic role in the generation of oxygen free radicals. Our data on LMW iron are in agreement with this theory: treatment with $\mathrm{HCB}+\mathrm{IMF}$ resulted in a $50 \%$ increase in $\mathrm{LMW}$ iron $(189.6 \pm 14.5 \mathrm{nmol} / \mathrm{g}$ wet wt liver tissue) as compared to IMF-treated mice. DFx reduced LMW iron in the HCB + IMF + DFx group $(135.5 \pm 8.5 \mathrm{nmol} / \mathrm{g}$ wet wt), which is confirmed by our data on MDA and porphyrin accumulation. The discrepancy in LMW iron between the IMF and $\mathrm{HCB}+\mathrm{IMF}$ groups could be the result of a reductive release of iron from ferritin, due to the generation of $\mathrm{O}_{2}$ by $\mathrm{HCB}[26,27]$. Whether radical-mediated processes damage URO-D itself, or cause the oxydation of uroporphyrinogens, is still an open issue, as our porphyrin measurements do not discriminate between porphyrins and porphyrinogens. However, the results on porphyrin accumulation and URO-D activity in the $\mathrm{HCB}+\mathrm{IMF}+\mathrm{DFx}$ group at 14 weeks are indicative of direct damage to URO-D, for the amount of porphyrins is already significantly diminished $(P<0.001)$ whereas URO-D activity is only slightly increased as compared to the results at 7 weeks (Figs 3 and 4 ).

In general, there seems to be a discrepancy 
between the results on MDA production and iron accumulation. After 4 weeks MDA production decreased, while iron was still accumulating in the hepatocytes. Iron storage in ferritin reduces the availability of catalytic iron for the generation of oxygen free radicals [25]. Ferritin synthesis is an iron-regulated process at the mRNA level [55] and, as mentioned before, morphological studies show that transport of iron from the injection site to the hepatocytes takes a considerable amount of time. Once iron reaches the hepatocytes, ferritin synthesis will be stimulated, but it is reasonable to assume that ferritin synthesis will not be able to accommodate this iron excess immediately. Eventually, most iron will be stored in ferritin, but in the meantime the amount of "free" iron (LMW iron) will probably be elevated and enhance the generation of oxygen free radicals.

We therefore conclude that iron is an important factor in porphyrin accumulation in C57BL/10, probably through its catalytic role in the generation of oxygen-related free radicals, resulting in direct damage to URO-D. The possible direct interaction between iron and URO-D, rendering the enzyme inactive, cannot be excluded, but seems hardly likely with regard to the very high iron concentrations necessary for this inactivation to occur. DFx's effectiveness in reducing porphyrin accumulation is most likely the result of a reduction in LMW iron, thus diminishing the amount of iron available for a catalytic role in the generation of oxygen-related free radicals.

\section{REFERENCES}

1. Sweeney GD, Porphyria cutanea tarda, or the uroporphyrinogen decarboxylase deficiency diseases. Clin Biochem 19: 3-15, 1986.

2. Marks GS, Exposure to toxic agents: the heme biosynthetic pathway and hemoproteins as indicator. CRC Crit Rev Toxicol 15: 151-179, 1985.

3. Taljaard JJF, Shanley BC, Deppe WM and Joubert SM, Porphyrin metabolism in experimental hepatic siderosis in the rat. II. Combined effect of iron overload and hexachlorobenzene. Br J Haematol 23: 513-519, 1972.

4. Louw M, Neethling AC, Percy VA, Carstens $M$ and Shanley BC, Effects of hexachlorobenzene feeding and iron overload on enzymes of haem biosynthesis and cytochrome P450 in rat liver. Clin Sci Mol Med 53: $111-115,1977$

5. Blekkenhorst GH, Day RS and Eales L. The effect of bleeding and iron administration on the development of hexachlorobenzene-induced rat porphyria. Int $J$ Biochem 12: 1013-1017, 1980.

6. Smith AG and Francis JE, Synergism of iron and hexachlorobenzene inhibits hepatic uroporphyrinogen decarboxylase in inbred mice. Biochem J 214: 909-913, 1983.

7. Smith AG, Francis JE, Dinsdale D, Manson MM and Cabral JRP, Hepatocarcinogenicity of hexachlorobenzene in rats and the sex difference in hepatic iron status and development of porphyria. Carcinogenesis 6: 631-636, 1985.

8. Alleman MA, Koster JF, Wilson JHP, EdixhovenBosdijk A, Slee RG, Kroos MJ and van Eijk HG, The involvement of iron and lipid peroxidation in the pathogenesis of HCB induced porphyria. Biochem Pharmacol 34: 161-166, 1985.

9. De Matteis F, Role of iron in the hydrogen peroxide-dependent oxidation of hexahydroporphyrins (porphyrinogens): a possible mechanism for the exacerbation by iron of hepatic uroporphyria. Mol Pharmacol 33: 463-469, 1988.

10. Smith AG, Francis JE, Cabral JRP, Carthew P, Manson MM and Stewart FP, Iron-enhancement of the hepatic porphyria and cancer induced by environmental polyhalogenated aromatic chemicals. Adv Biosci 76: 203-214, 1989.

11. Smith $A G$ and De Matteis F, Oxidative injury mediated by the hepatic cytochrome P-450 system in conjunction with cellular iron. Effects on the pathway of haem biosynthesis. Xenobiotica 20: 865-877, 1990.

12. Siersema PD, van Helvoirt RP, Ketelaars DAM, Cleton MI, de Bruijn WC, Wilson JHP and van Eijk HG, Iron and uroporphyrin in hepatocytes of inbred mice in experimental porphyria: a biochemical and morphological study. Hepatology 14: 1179-1188, 1991.

13. Wainstok de Calmanovici R, Billi SC, Aldonatti CA and San Martin de Viale LC, Effect of desferrioxamine on the development of hexachlorobenzene-induced porphyria. Biochem Pharmacol 35: 2399-2405, 1986.

14. Barry M, Flynn DM, Letsky EA and Risdon RA, Long term chelation therapy in thallasaemia major: effect on liver iron concentration, liver histology and clinical progress. Br Med J 2: 16-20, 1974.

15. Ferioli A, Harvey $C$ and De Matteis F, Drug-induced accumulation of uroporphyrin in chicken hepatocyte cultures. Structural requirements for the effect and role of exogeneous iron. Biochem J 224: 769-777, 1984.

16. Sweeney GD, Jones KG, Cole FM, Basford D and Krestynski F, Iron deficiency prevents liver toxicity of 2,3,7,8-tetrachlorodibenzo-p-dioxin. Science 204: 332335,1979

17. Rizzardini $M$, Graziani $A$, Carugo $C$ and Cantoni $L$, Investigations on the role of free radical processes in hexachlorobenzene-induced porphyria in mice. $J$ Biochem Toxical 3: 33-46, 1988.

18. Visser $O$, van den Berg JWO, Edixhoven-Bosdijk $A$ Koole-Lesuis R, Rietveld $T$ and Wilson JHP, Development of hexachlorobenzene porphyria in rats: time sequence and relationship with lipid peroxidation. Food Chem Toxicol 27: 317-321, 1989.

19. Mukerji SK and Pimstone NR, Free radical mechanism of oxidation of uroporphyrinogen in the presence of ferrous iron, Arch Biochem Biophys 281: 177-184, 1990.

20. Freeman BA and Crapo JD, Biology of disease: free radicals and tissue injury. Lab Invest 47: 412, 1982.

21. Halliwel $B$ and Gutteridge JMC, The importance of free radicals and catalytic metal ions in human diseases. Mol Aspects Med 8: 89-193, 1985.

22. Braughier JM, Chase RL and Pregenzer JF, Oxidation of ferrous iron during peroxidation of lipid substrates. Biochim Biophys Acta 921: 457-464, 1987.

23. Cadenas E, Biochemistry of oxygen toxicity. Annu Rev Biochem 58: 79-110, 1989.

24. Aust SD and Svingen BA, The role of iron in enzymatic lipid peroxidation. In: Free Radicals in Biology (Ed. Pryor WA), Vol. V, pp. 1-28. Academic Press, New York, 1982.

25. Munro $\mathrm{HN}$ and Linder $\mathrm{MC}$, Cells sequence $\mathrm{Fe}^{2+}$ in ferrules. Physiol Rev 58: 433-439, 1978.

26. De Matteis $F$ and Stonard M, Experimental porphyrias as models for human hepatic porphyrias. Semin Hematol 14: 187-192, 1977.

27. Rowley B and Sweeney GD, Release of ferrous iron from ferritin by liver microsomes: a possible role in the toxicity of 2,3,7,8-tetrachlorodibenzo-p-dioxin. Can J Biochem Cell Biol 62: 1293-1300, 1984. 
28. Koster JF and Slee RG, Ferritin, a physiological iron donor for microsomal peroxidation. FEBS Lett 199: 85-88, 1986.

29. Sweeney G, Basford D, Rowley B and Goddard G, Mechanisms underlying the hepatotoxicity of 2,3,7,8tetrachlorodebenzo-p-dioxin. Banbury Rep 18: 225237, 1984.

30. Jacobs $A$, Low molecular weight intracellular iron transport compounds. Blood 50: 433-439, 1977.

31. Egyed A, Cellular iron metabolism: aspects of regulation. In: The Biochemistry and Physiology of Iron (Eds. Saltman P and Henegauer J), pp. 103-119. Elsevier North Holland, Amsterdam, 1982.

32. Morley CGD, Rewers $K$ and Bezkorovainy $A$, The pathway of iron from serum transferrin to liver ferritin in the rat. In: The Biochemistry and Physiology of Iron (Eds. Saltman $P$ and Henegauer J), pp. 171-172. Elsevier North Holland, Amsterdam, 1982.

33. Fontecave $M$ and Pierre JL, Iron metabolism: the lowmolecular-mass iron pool. Biol Metal 4: 133-135, 1991.

34. Wills ED, Lipid peroxide formation in microsomes. The role of non-haem iron. Biochem $J$ 113: 325-332, 1969.

35. Voogd A, Sluiter W, van Eijk HG and Koster JF, Low molecular weight iron and the oxygen paradox in isolated rat hearts. J Clin Invest 90: 2050-2055, 1992.

36. Lim CK, Famei LI and Peters TJ, Review: high performance liquid chromatography of porphyrins. $J$ Chromatogr 429: 123-153, 1988.

37. Jordan PM, Uroporphyrinogen III cosynthetase: a direct assay method. Enzyme 28: 158-166, 1982.

38. Lowry OH, Rosebrough NJ, Farr AL and Randall RJ, Protein measurement with the Folin phenol reagent. J Biol Chem 193: 265-275, 1951.

39. Straka JG, Kushner JP and Pryor MA, Uroporphyrinogen decarboxylase. A method for measuring enzyme activity. Enzyme 28: 170-182, 1982.

40. Harris DC, Iron exchange between ferritin and transferrin in vitro. Biochemistry 17: 3071-3078, 1978.

41. Bradford MM, A rapid and sensitive method for the quantitation of microgram quantities of protein utilizing the principle of protein-dye binding. Anal Biochem 72: 248-254, 1976.

42. Kornbrust DJ and Mavis RD, Relative susceptibility of microsomes from lung, heart, liver, kidney, brain and testes to lipid peroxidation: correlation with vitamin E content. Lipids 15: 315-324, 1980.

43. Wilson JHP, van den Berg JWO, Edixhoven-Bosdijk $A$ and van den Gastel-Quist LHM, Preparation of porphyrin methylesters for high pressure liquid chromatography. Clin Chim Acta 89: 165-167, 1978.

44. Mukerji SK and Pimstone NR, In vitro studies of the mechanism of inhibition of rat liver uroporphyrinogen decarboxylase activity by ferrous iron under anaerobic conditions. Arch Biochem Biophys 244: 619-629, 1986.

45. Mukerji SK, Pimstone NR and Burns $M$, Dual mechanism of inhibition of rat liver uroporphyrin decarboxylase activity by ferrous iron: its potential role in the gencsis of porphyria cutanca tarda. Gastroenterology 87: 1248-1254, 1984.

46. Mukerji SK, Pimstone NR and Tan KT, A potential biochemical explanation for the genesis of porphyria cutanea tarda. FEBS Lett 189: 217-220, 1985.

47. Woods JS, Metal alteration of uroporphyrinogen decarboxylase and coproporphyrinogen oxidase. Ann NY Acad Sci 514: 55-64, 1987.

48. Lambrecht RW, Jacobs JM, Sinclair PR and Sinclair $\mathrm{JF}$, Inhibition of uroporphyrinogen decarboxylase activity. The role of cytochrome P-450-mediated uroporphyrinogen oxidation. Biochem $J$ 269: 437-441, 1990.

49. Kozlov AV, Yegorov DY, Vladimirov YA and Azizova $O A$, Intracellular free iron in liver tissue and liver homogenate: studies with electron paramagnetic resonance on the formation of paramagnetic complexes with Desferal and nitric oxide. Free Rad Biol Med 13: 9-16, 1992.

50. Siersema PD, Cleton-Soeteman MI, de Bruijn WC, ten Kate FJW, van Eijk HG and Wilson JHP, Ferritiniron accumulation and uroporphyrin (crystal) formation in hepatocytes of C57BL/10 mice: a time-course study. Cell Tissue Res, in press

51. Hahn ME, Gasiewicz TA, Linko P and Goldstein JA, The role of the Ah locus in hexachlorobenzene-induced porphyria. Studies in congenic C57BI/6J mice. Biochem J 254: 245-254, 1988.

52. Jacobs JM, Sinclair PR, Bement WJ, Lambrecht RW, Sinclair JF and Goldstein JA, Oxidation of uroporphyrinogen by methylcholantrene-induced cytochrome P-450. Essential role of cytochrome P450d. Biochem J 258: 247-253, 1989.

53. Urquhart $A J$ and Fider GH, Hexachlorobenzeneinduced oxygen activation by mouse liver microsomes: comparison with phenobarbitone and 20-methylcholanthrene. Biochem Pharmacol 36: 3795-3796, 1987.

54. Sweeney GD, Jones KG, Cole FM, Basford D and Krestynki F, Iron prevents liver toxicity of $2-, 3-, 7-, 8-$ tetra-chlorodibenzo-p-dioxin. Science 204: 332-335, 1979.

55. Hentze MW, Wright Caughman S, Casey JL, Koeller DM, Rouault TA, Harford JB and Klausner RD, A model for the structure and functions of iron-responsive elements. Gene 72: 201-208, 1988. 